\title{
Electrochemotherapy in Breast Cancer - Discussion of the Method and Literature Review
}

\author{
Mateusz Wichtowski ${ }^{a} \quad$ Dawid Murawa $^{\mathrm{b}}$ Katarzyna Kulcenty ${ }^{\mathrm{c}}$ Karolina Zaleska $^{\mathrm{c}}$ \\ ${ }^{a}$ Oncological and General Surgery Ward I, Greater Poland Cancer Center, Poznan, Poland; \\ ${ }^{b}$ Department of General and Minimally Invasive Surgery, Poland Baptism Monument Hospital, Gniezno, Poland; \\ ${ }^{\mathrm{c}}$ Radiobiology Laboratory, Greater Poland Cancer Centre, Poznan, Poland
}

\section{Keywords}

Bleomycin · Breast cancer · Electrochemotherapy

\section{Summary}

Breast cancer is the most common cause of skin metastases in women. The probability of their occurrence ranges from about $5 \%$ in the entire population to as much as $30 \%$ in the late stages of the disease. Although rarely life-threatening, they have a major impact on the quality of life of patients with this diagnosis, being the cause of pain, effusion, ulceration, infection, and psychological discomfort. Available methods of treatment, both local and systemic, often fail to provide adequate control of the disease. A particular challenge seems to be the treatment of those patients with cutaneous metastases who, due to the extent of their metastases, are not eligible for resection, in whom the possibility of radiation therapy has already been used, and in whom systemic therapy is ineffective or contraindicated. A new method providing the opportunity for effective treatment is electrochemotherapy (ECT). ECT combines electropulsation of tumor cells (by local application of electric pulses) and administration of antineoplastic drugs such as cisplatin or bleomycin (either intravenous or intratumoral). Several clinical studies have demonstrated that ECT provides safe, efficient, and non-invasive locoregional treatment for chest wall breast cancer recurrence.

(c) 2017 S. Karger GmbH, Freiburg

\section{Introduction}

Over the last decade, breast cancer has become the most common cancer in women. As a result of an increase in the detection of the disease at an early stage and the development of new anticancer therapies, it has also become one of the cancers with the highest cure rate. Nevertheless, 5-30\% of patients experience local skin recurrence (chest wall recurrence, CWR) within 10 years of mastectomy [1-3]. This recurrence may be the only symptom of an active cancer, but it may also be accompanied by dissemination of the disease to other organs.

CWR usually takes the form of multiple nodules in the skin and subcutaneous tissue, which, without treatment, most frequently become ulcerated, bleed, and cause chronic pain. The quality of life of these patients is dramatically reduced. It has been proven that various factors such as the size of the primary tumor, the tumor phenotype, and invasion of blood vessels affect the frequency of CWR after mastectomy [4].

The spread of breast cancer to the skin is not always associated with a poor prognosis, especially in the absence of markers for systemic spread and when surgical resection of the recurrent cancer is possible [5]. Resection may be supplemented with radiotherapy (RT) and systemic treatment.

Where surgery, RT, and systemic treatments have already been explored, or where they fail to produce positive results, the possibilities for achieving local control are limited. One of the new methods providing the opportunity for effective treatment is electrochemotherapy (ECT).

\section{Electrochemotherapy}

ECT involves the non-thermal ablation of tumor tissue [6]. To this end, it uses the phenomenon of reverse electroporation. The basis for this method is the application of an external electric field to the target tissue. Electric pulses of appropriate intensity and du-

\section{KARGER}

(๑) 2017 S. Karger GmbH, Freiburg
Dr. Mateusz Wichtowski

Oncological and General Surgery Ward I

Greater Poland Cancer Center

Poznań, Poland

mawichto@gmail.com 


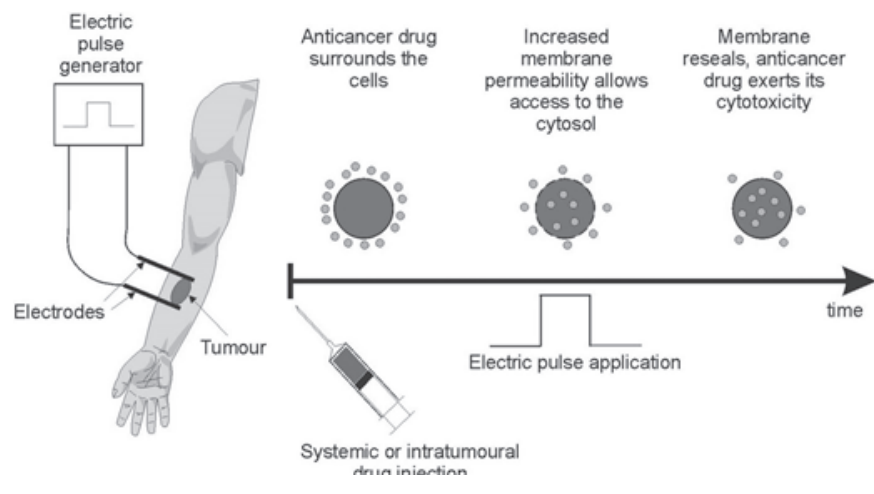

Fig. 1. Flow chart presenting steps of electrochemotherapy (courtesy of IGEA, Carpi, Italy).

ration induce changes in the structure of the cell membrane, and pores are formed making it non-selectively permeable. If at the same time a cytostatic agent is present in the extracellular space, it will permeate to the center of the cell as a result of a simple diffusion mechanism. A few minutes after the impulse, the cell membrane regains homeostasis, and high concentrations of the cytostatic agent remain in the cytosol. As a result, the potential toxicity increases significantly [7]. A flow chart demonstrating the ECT procedure is shown in figure 1.

Currently, bleomycin and cisplatin are the most commonly used chemotherapeutic agents, mainly due to the fact that, if used conventionally, they present with poor penetration into the cell center, while under the influence of electroporation their concentration in the cytosol, and thus their toxicity, increase significantly. In vitro studies demonstrated that in combination with electroporation toxicity is increased up to 1,000 times for bleomycin and 80-100 times for cisplatin $[8,9]$.

Bleomycin is an anticancer polypeptide antibiotic with a minimal indicator of myelotoxicity [10]. It can induce interstitial plasma cell pneumonia which in some cases leads to interstitial fibrosis. Pulmonary toxicity is recorded in about $10 \%$ of patients, and lung fibrosis develops in $10 \%[11,12]$. There is a correlation between the total dose of bleomycin received and the risk of pulmonary fibrosis; the dose of $400,000 \mathrm{IU} / \mathrm{m}^{2}$ should not be exceeded. Two-thirds of the administered bleomycin is excreted unchanged in the urine; patients with renal failure may have elevated levels in the blood. Therefore, the dose of bleomycin should be modified depending on the estimated glomerular filtration rate. At the cellular level, bleomycin leads to single- and double-stranded damage within the DNA helix, and it is an inhibitor of DNA-dependent polymerase. It causes fragmentation of DNA strands [13].

The ETC protocol allows the administration of bleomycin intratumorally as well as intravenously. Topical application (into the tumor) is legitimate if $<7$ nodules of small diameter $(<20 \mathrm{~mm})$ are to be included in the therapy [14-16]. The dosage of the cytostatic agent used topically depends on the size of the tumor and is set out in the document titled 'Standard operating procedures of electrochemotherapy (...)' (SOP) [14]. First studies comparing the efficacy of bleomycin administered topically versus in combination with electroporation demonstrated more than 2 times better results in the case of ECT (complete response (CR) 31 vs. 78\%) [17]. In the case of more and larger tumors, intravenous administration of bleomycin is preferred; the dose is $15,000 \mathrm{IU} / \mathrm{m}^{2}$ in such cases. This dose is similar to that used in classic systemic chemotherapy with bleomycin; however, during ECT, only 1 bolus of the chemotherapeutic agent is administered which usually does not lead to the toxicity threshold being reached.

Cisplatin affects DNA similarly to bleomycin, damaging its structure and leading to the initiation of cell apoptosis [18]. 90\% of cisplatin is excreted through the kidneys; hence, prior to its administration, diagnostic tests should be carried out for chronic kidney disease, and, in order to prevent nephrotoxicity, the patient should be well hydrated. $2 \mathrm{~h}$ after administration of $90 \%$ of cisplatin, it binds to plasma proteins. Under ECT, cisplatin is administered intratumorally; the exact doses are specified in the SOP protocol [14].

The final outcome of ECT is affected by a number of other elements besides the described increase in toxicity of the cytostatic drugs as a result of electroporation. First, electric current pulses cause contraction of the surrounding blood vessels, which results in a temporary reduction in perfusion and a delay in the chemotherapeutic agent being transported away from the tumor (socalled vascular lock) $[19,20]$. Second, ECT locally limits the process of neovascularization due to its pro-apoptotic properties affecting also endothelial cells $[21,22]$. Third, stimulation of the systemic immune response also exerts an influence on the final outcome of therapy. The use of ECT on the tumor tissue induces massive necrosis, and the disintegrating cells release tumor antigens which in large amounts enhance the natural immune response; thus, this effect may be responsible for a systemic response to the topical treatment $[23,24]$.

\section{ECT Technique}

Standard procedures for the use of ECT, including the protocols on administration of cytostatic agents, were developed in 2006 in the form of 2 documents: the European Standard Operating Procedures of Electrochemotherapy (ESOPE) [7] and the aforementioned SOP [14]. These provide guidelines for the use of ECT to this day. The procedure can be performed under local or general anesthesia and can be repeated several times, even in patients with coexisting diseases. Both described cytostatic drugs remain in use, and their administration commences the procedure. Bleomycin or cisplatin are administered intratumorally for about $1 \mathrm{~min}$ prior to the application of the first pulse of electric current. In the case of intravenous administration of bleomycin as a bolus lasting approximately $1 \mathrm{~min}$, the first application of current occurs after $8 \mathrm{~min}$. After $8 \mathrm{~min}$ of waiting for the proper concentration of the cytotoxic drug in the circulating blood, electroporation is carried out in the intended area for another $20 \mathrm{~min}$ [14].

The ESOPE guidelines were prepared based on the use of a device called Cliniporator ${ }^{\mathrm{TM}}$ (IGEA.r.l., Carpi, Italy) (fig. 2). 1 application consists of 8 consecutive pulses of electric current with a voltage of $400-700 \mathrm{~V}$, a duration of $100 \mu$ s, and a frequency of $5,000 \mathrm{~Hz}$. The pulses are delivered by means of needle electrodes. 


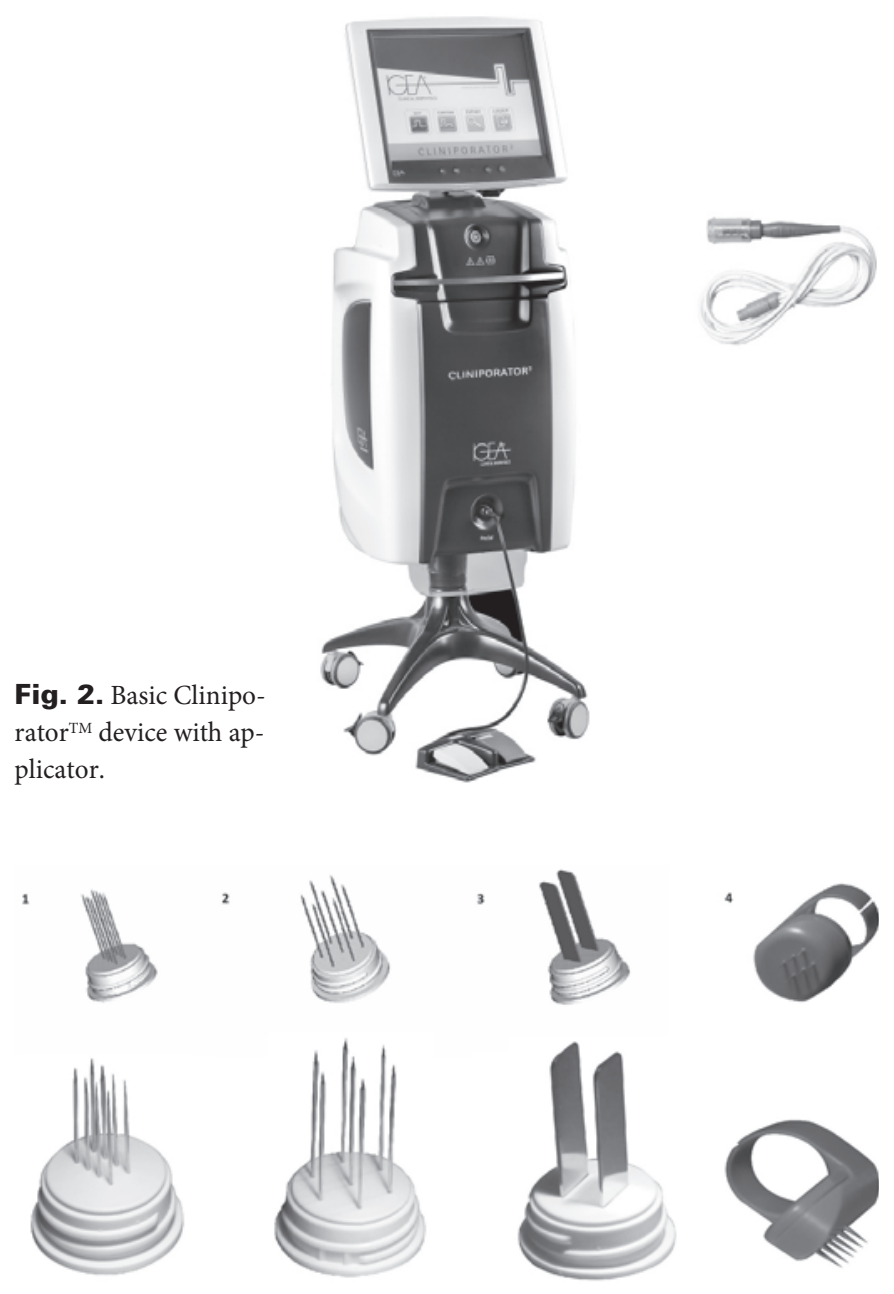

Fig. 3. Types of needle electrodes: 1 , linear; 2 , hexagonal; 3 , plate; 4 , ring.

The manufacturer provides several types of electrodes dedicated to different lesion sizes and locations (fig. 3). The maximum electrode length is $3 \mathrm{~cm}$, and lesions located within that depth range are suitable for this therapy.

The main contraindications for ECT include renal failure, allergy to bleomycin or cisplatin, pulmonary fibrosis (in the case of bleomycin), epilepsy, and a pacemaker. Nevertheless, according to the literature, ECT demonstrates a low toxicity profile with limited and mostly minor side effects. Main complications are local and include local pain, swelling, redness, ulcers (due to necrosis of originally exophytic tumors), and depigmentation [14].

\section{Aim, Material, and Methods}

In the current paper, the method of ECT is discussed and a review of literature presented concerning the treatment of breast cancer metastasis to the skin and subcutaneous tissue with ECT. The literature review included 5 databases: PubMed, HighWire Press, Science Direct, Wiley Online Library, and Google Scholar. Initially, 409 publications were selected by searching the phrases 'electrochemotherapy' and 'breast cancer'. We searched for publi-

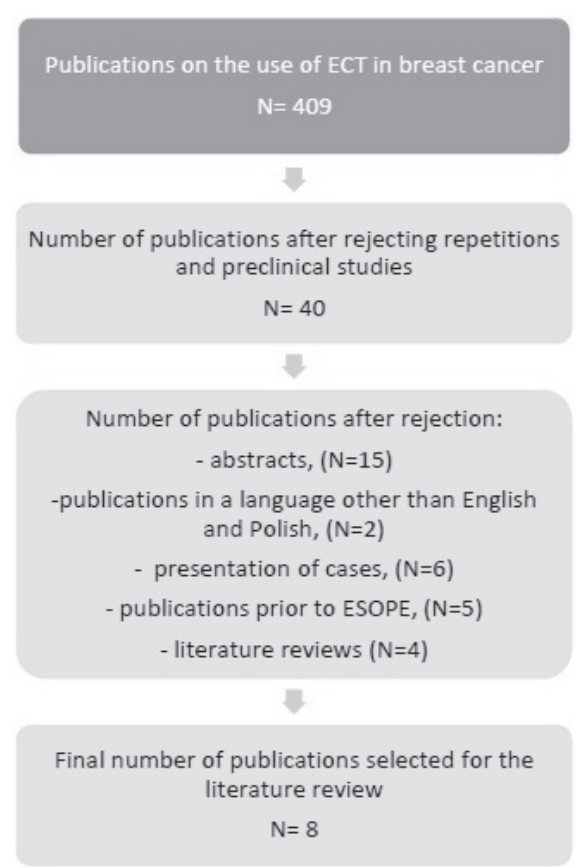

Fig. 4. Process of selection of publications included in the literature review.

cations on studies carried out after the publication of the ESOPE standards, i.e. from August 2006 until October 2016. After a preliminary analysis, we rejected papers repeated in different databases, papers on preclinical studies, works only in the form of abstracts, publications in languages other than English and Polish, works in the form of presentations of clinical cases, literature reviews, and publications prepared on the basis of data before the ESOPE study. We also excluded papers which described results of ECT on heterogeneous groups of patients, where a group of patients with breast cancer was not clearly isolated. Ultimately, 8 original papers qualified for inclusion in the literature review. The scheme for the selection of publications is presented in figure 4 .

\section{Results}

All papers on ECT published after August 2006 referred to ESOPE in which results of multicenter studies aimed at establishing guidelines for the use of ECT were presented for the first time [7]. The study included 61 patients from 4 European centers. Both bleomycin and cisplatin were used as cytostatic agents. Bleomycin was administered both intratumorally and intravenously. Cisplatin was administered intratumorally only. The final response to treatment was evaluated in 41 patients. Overall response (OR) to treatment amounted to $84.8 \%$ (including CR, 73.7\%). No statistically significant differences were observed between the results of ECT with bleomycin or cisplatin as well as between the different routes of delivery. One limitation of this study was that the only isolated homogenous group included patients diagnosed with melanoma. Hence, this work, despite its fundamental value for the current indications for the use of ECT, was not included in the list of publications selected for this literature review. All 8 publications included in the discussion are presented in table 1. 
Table 1. Selected publications on the use of electrochemotherapy (ECT) in the treatment of breast cancer metastasis to the skin and subcutaneous tissue

\begin{tabular}{|c|c|c|c|c|c|c|c|c|c|c|}
\hline \multirow{2}{*}{$\begin{array}{l}\text { Author, } \\
\text { year [ref.] }\end{array}$} & \multirow{2}{*}{$\begin{array}{l}\text { Patients, } \\
\mathrm{n}\end{array}$} & \multirow{2}{*}{$\begin{array}{l}\text { Lesions, } \\
\mathrm{n}\end{array}$} & \multirow{2}{*}{$\begin{array}{l}\text { Drug/ } \\
\text { delivery route }\end{array}$} & \multirow{2}{*}{$\begin{array}{l}\text { ECT } \\
\text { courses, } \mathrm{n}\end{array}$} & \multicolumn{4}{|c|}{ Response to treatment, \% } & \multirow[t]{2}{*}{ Follow-up } & \multirow[t]{2}{*}{ LPFS } \\
\hline & & & & & CR & PR & SD & $\mathrm{PD}$ & & \\
\hline $\begin{array}{l}\text { Skarlatos, } \\
2011[6]\end{array}$ & 8 & $\mathrm{BD}$ & $\begin{array}{l}\text { bleomycin i.v. } \\
\text { or i.t. }\end{array}$ & 13 (avg 1.6) & 25 & 75 & 0 & 0 & 60 days & ND \\
\hline $\begin{array}{l}\text { Kreuter, } 2014 \\
\quad[28]\end{array}$ & 13 & $\mathrm{BD}$ & bleomycin i.v. & 20 (avg 1.5) & 7.7 & 38.5 & 15.4 & 38.5 & ND & ND \\
\hline $\begin{array}{l}\text { Cabula, } 2015 \\
\text { [25] }\end{array}$ & 113 & 214 & $\begin{array}{l}\text { bleomycin i.v. } \\
\text { or i.t. }\end{array}$ & 113 (avg 1) & 58.4 & 31.8 & 7.1 & 1.8 & $\begin{array}{l}\text { min. } 8 \text { weeks } \\
\text { (avg } 5.9 \text { months) }\end{array}$ & $\begin{array}{l}\text { 12-month LPFS } 86.2 \% \text {; } \\
\text { in group with CR } 96.4 \%\end{array}$ \\
\hline $\begin{array}{l}\text { Campana, } \\
2014 \text { [29] }\end{array}$ & 55 & 212 & $\begin{array}{l}\text { bleomycin i.v. } \\
\text { or i.t. }\end{array}$ & ND (avg 2) & 40 & 47.3 & 12.7 & 0 & $\begin{array}{l}\text { min. } 8 \text { weeks } \\
\text { (avg } 32 \text { months) }\end{array}$ & $\begin{array}{l}2 \text {-year LPFS }<70 \text { years of } \\
\text { age } 93 \% ;>70 \text { years } 67 \%\end{array}$ \\
\hline $\begin{array}{l}\text { Campana, } \\
2012[38]\end{array}$ & 35 & 516 & bleomycin i.v. & $62(\operatorname{avg} 1.8)$ & 54.3 & 37.1 & 8.6 & 0 & $\begin{array}{l}\text { min. } 8 \text { weeks } \\
\text { (avg } 32 \text { months) }\end{array}$ & 36-month LPFS 81\% \\
\hline $\begin{array}{l}\text { Matthiessen, } \\
2012 \text { [27] }\end{array}$ & 12 & 25 & bleomycin i.v. & 27 (avg 2.2) & 8 & 8 & 76 & 8 & $\begin{array}{l}\min .8 \text { weeks } \\
\text { (avg } 11 \text { weeks) }\end{array}$ & ND \\
\hline $\begin{array}{l}\text { Benavento, } \\
2012[26]\end{array}$ & 12 & 142 & bleomycin i.v. & $16(\operatorname{avg} 1.3)$ & 75.3 & 17 & 7.7 & 0 & $\begin{array}{l}\min .4 \text { weeks } \\
\text { (avg } 30 \text { weeks) }\end{array}$ & ND \\
\hline $\begin{array}{l}\text { Wichtowski, } \\
2016 \text { [39] }\end{array}$ & 7 & 35 & bleomycin i.v. & 9 (avg 1.3) & 43 & 43 & 0 & 14 & $\begin{array}{l}\min .8 \text { weeks } \\
\text { (avg } 12 \text { weeks) }\end{array}$ & ND \\
\hline \multirow{2}{*}{$\begin{array}{l}\text { Total/ } \\
\text { average }\end{array}$} & 255 & 1,454 & & & 39 & 37 & 16 & 8 & & \\
\hline & & & & & \multicolumn{4}{|c|}{$\mathrm{OR}=76 \%$} & & \\
\hline
\end{tabular}

$\mathrm{CR}=$ Complete response; $\mathrm{PR}=$ partial response; $\mathrm{SD}=$ stable disease; $\mathrm{PD}=$ progressive disease; $\mathrm{LPF}=$ local progression-free survival; i.v. $=$ intravenous; i.t. = intratumoral; $\min .=$ minimum; avg $=$ average $\mathrm{ND}=$ no data; $\mathrm{OR}=$ overall response.

The largest group of patients was gathered by Cabula et al. [25] in their paper published in 2015 in which the results on 113 patients and a total of 214 lesions treated with ECT are presented. Similar to most studies, the authors used bleomycin administered intravenously or intratumorally depending on lesion number and size in a given patient. The overall percentage of positive responses within a 2-month follow-up amounted to $90.2 \%$, including CR in $58.4 \%$ of patients. With regard to long-term results, $86.2 \%$ of patients achieved a 12-month period free from local progression, and in the group of CR patients this percentage was $96.4 \%$. In multivariate analysis, the factors which were statistically significant in achieving CR included: tumor size $<3 \mathrm{~cm}$, absence of visceral metastases, positive expression of estrogen receptor, and Ki-67 index $<14 \%$. The most common complications included: sharp pain in the first $48 \mathrm{~h}$ after surgery; in the long-term follow-up, $8 \%$ of patients experienced grade 3 ulcers and $8.8 \%$ grade 2 hyperpigmentation according to Common Toxicity Criteria (CTC).

The best results in terms of CR were obtained by Benavento et al. [26] who applied ECT in 12 patients with a total of 142 lesions. Response to treatment was assessed after 30 days, and the median follow-up time was 210 days. The percentage of CR amounted to $75.3 \%$; after adding the percentage of partial responses (PR; 17\%) the overall percentage of positive responses was at the level of $92.3 \%$ (OR). Patients received $1-3$ courses of treatment. No serious complications were observed in relation to the ECT procedure. 1 patient experienced sharp pain for $48 \mathrm{~h}$, another experienced ulceration persisting after surgery, which was due to necrosis of the tumor tissue.
The most skeptical results were published by Matthiesen et al. [27] and similarly by Kreuter et al. [28]. In the former, the CR rate amounted to $8 \%$, the PR rate was also $8 \%$, and the percentage of lesions assessed as stabilized (lack of progression, stable disease (SD)) was $76 \%$. In the latter, CR was $7.7 \%$, but PR amounted to $38.5 \%$, which adds up to an OR of $46.2 \%$. In the case of the publication by Matthiesen et al. [27], it should be noted, however, that the response to treatment was evaluated only in tumors $>3 \mathrm{~cm}$ in diameter, while many other studies suggested that the effectiveness of ECT is dramatically reduced in tumors $>3 \mathrm{~cm}$. In the study by Matthiesen et al. [27], a complication was observed in the form of chronic neuropathic pain with grade 3 intensity based on CTC. This is a complication which was not observed during treatment of smaller diameter lesions.

Interesting results were presented by Campana et al. [29] in their paper published in 2014. The authors obtained satisfactory overall results, yielding an overall percentage of positive responses of $87.3 \%$. When assessing the period free from recurrence within a 2 -year observation, it was noted that statistically better results were achieved in patients $<70$ years of age (93 vs. $67 \%$ ); however, disease progression was more frequently observed in the group $<70$ years of age than in the group $>70$ years of age, and most frequently it affected areas outside the initial ECT treatment (39 vs. 30\%). When describing the incidence of recurrence outside the ECT therapy area at $60 \%$ referring to the entire group of patients included in the study, the authors emphasized how important it is to understand that ECT is a palliative method of local treatment. The complications reported in his study were similar to those mentioned by other authors and included postoperative pain and ulcers. 


\section{Summary}

In the case of limited metastases from breast cancer to the skin and subcutaneous tissue, surgery remains the main therapeutic option. Often, however, unresectable, extensive, ulcerating recurrence around the mastectomy scar presents as the only symptom of cancer recurrence and constitutes a therapeutic challenge for the surgical oncologist. From the patient's perspective, it causes significant reduction in quality of life. The most available and, therefore, most frequently used intervention in the case of cutaneous metastatic cancer ineligible for surgery is systemic chemotherapy which is often ineffective. Other methods used include RT and local techniques such as photodynamic therapy (PDT) and local chemotherapy (intralesional therapy, ILT). A metaanalysis published in 2014 presenting results of 47 prospective studies compared 5 available therapies used for skin cancers: ECT, RT, PDT, ILT, and systemic cytotoxic treatment. In the case of ECT, the OR was $75.4 \%$ (CR $47.5 \%$ ), with a low toxicity profile ( $\geq 3$ toxicity based on the CTC toxicity scale in less than $6 \%$ of patients). OR was $62.7 \%$ for RT, $67.8 \%$ for PDT, $21.4 \%$ for ILT, and $12.9 \%$ for systemic therapy [30]. In the presented meta-analysis, metastatic breast cancer and melanoma recurrence accounted for $96.8 \%$ of cases.

The effectiveness of ECT has been proven in the treatment of many cancers including melanoma, Kaposi's sarcoma, leiomyosarcoma, breast cancer metastasis, head and neck cancer, and primary skin cancers [6, 31-33]. Most frequently, it is a palliative treatment at a time when other methods have failed to produce positive results [34]. However, due to the proven efficacy, it may also be used as a method of choice in the case of contraindications to surgery and RT, e.g. to palliatively treat bleeding ulcers.
The new generation of ECT devices (Cliniporator Vitae which is still undergoing clinical trials) is equipped with electrodes with a length and shape enabling the treatment of tumors of parenchymatous organs such as liver and pancreas $[35,36]$. There is also an open avenue to combine ECT with immunotherapy. Interesting data were provided by preclinical studies in mice, which compared the use of ECT in immunocompetent mice versus mice with immune disorders [24]. High efficiency with a statistically significant difference was demonstrated in the first group.

Most studies concerning the use of ECT in breast cancer describe its effectiveness in the treatment of cutaneous metastasis after mastectomy. In the future, once the device and electrodes have been upgraded, the extension of its application also to primary breast cancer should be considered, e.g. as a neoadjuvant therapy for tumors with $\geq \mathrm{T} 3$ features, replacing the long-term preoperative systemic chemotherapy. In 2013, Cabula [37] published positive results achieved in a patient treated with ECT for primary breast cancer. The author concluded that research in this area should be continued.

The main advantages of ECT include high efficacy, duration of response to treatment, reduced toxicity, and quick and full recovery after surgery. This, combined with the simplicity of the procedure itself, makes it a useful therapeutic option, especially in patients with stage 4 cancer.

\section{Disclosure Statement}

The authors have no conflict of interest to declare.

The authors received financial support from IGEA to cover publication costs. The authors declare that they have not received any gratification from IGEA.

\section{References}

1 Overgaard M, Hansen PS, Overgaard J, et al.: Postoperative radiotherapy in high-risk premenopausal women with breast cancer who receive adjuvant chemotherapy. Danish Breast Cancer Cooperative Group 82b Trial. N Engl J Med 1997;337:949-955.

2 Nielsen HM, Overgaard M, Grau C, et al.: Study of failure pattern among high-risk breast cancer patients with or without postmastectomy radiotherapy in addition to adjuvant systemic therapy: long-term results from the Danish Breast Cancer Cooperative Group DBCG $82 \mathrm{~b}$ and $\mathrm{c}$ randomized studies. J Clin Oncol 2006;24:2268-2275.

3 Lee MC, Jagsi R: Postmastectomy radiation therapy: indications and controversies. Surg Clin North Am 2007;87:511-526.

4 Van der Pol CC, van Geel AN, Menke-Pluymers MB, et al.: Prognostic factors in 77 curative chest wall resection for isolated breast cancer recurrence. Ann Surg Oncol 2009;16:3414-3421.

5 Chagpar A, Meric-Bernstam F, Hunt KK, et al.: Chest wall recurrence after mastectomy does not always portend a dismal outcome. Ann Surg Oncol 2003;10:628634.

6 Skarlatos I, Kyrgias G, Mosa E, et al.: Electrochemotherapy in cancer patient: first clinical trial in Greece. In Vivo 2011;25:265-274.
7 Marty M, Sersa G, Garbay JR, et al.: Electrochemotherapy - an easy, highly effective and safe treatment of cutaneous and subcutaneous metastases: results of ESOPE (European Standard Operating Procedures of Electrochemotherapy) study. EJC Suppl 2006;4:3-13.

8 Orlowski S, Belehradek J Jr, Paoletti C, et al.: Transient electropermeabilization of cells in culture. Increase of the cytotoxicity of anticancer drugs. Biochem Phar 1988;37:4727-4733.

9 Larkin JO, Collins CG, Aarons S, et al.: Electrochemotherapy: aspects of preclinical development and early clinical experience. Ann Surg 2007;245:469-479.

10 Umezawa H: Bleomycin and other antitumor antibiotics of high molecular weight. Antimicrob Ag Chem Ther 1965;5:1079-1085.

11 Ichikawa T: A new anti-neoplastic agent, bleomycin-its effect on squamous cell carcinoma. Nihon Ishikai Zasshi 1969;61:487-497.

12 Schmidt-Matthiesen H, Bastert G, Wallwiener D: Gynäkologische Oncologie: Diagnostic, Therapie und Nachsorge - auf der Basis der AGO-Leitlinien, 7. Aufl. Stuttgart, Schattauer Verlag, 2002.

13 Lüllmannn H, Mohr K, Wehling M: Pharmakologie und Toxikologie: Arzneimittelwirkungen versehen Medikamente gezielt einsetzen, 15.Aufl. Stuttgart, Tieme, 2003, p. 476
14 Lluis M, Gehl J, Sersa G, et al.: Standard operating procedures of the electrochemotherapy: instructions for the use of bleomycin or cisplatin administered either systemically or locally and electric pulses delivered by the Cliniporator by means of invasive or non-invasive electrodes. EJC Suppl 2006;4:14-25.

15 Sersa G, Miklavic D: Electrochemotherapy of tumours. J Vis Exp 2008;22:pii:1038.

16 Moller MG, Salwa S, Soden DM, et al.: Electrochemotherapy as an adjunct or alternative to other treatments for unresectable or in-transit melanoma. Expert Rev Antican Ther 2009;9:1611-1630.

17 Testori A, Tosti G, Martinoli C, et al.: Electrochemotherapy for cutaneous and subcutaneous tumor lesions: a novel therapeutic approach. Dermatol Ther 2010;23:651-661.

18 Schmidt G, Juhasz-Böss, Solomayer EF, et al.: Electrochemotherapy in breast cancer: a review of references. Gebursh Frauenheilk 2014;74:557-562.

19 Jarm T, Cemazar M, Miklavcic D, et al.: Antivascular effect of electrochemotherapy: implications in treatment of bleeding metastases. Expert Rev Anticancer Ther 2010;10:729-746.

20 Sersa G, Cemazar M, Parkins CS, et al.: Tumour blood flow changes induced by application of electric pulses. Eur J Cancer 1999;35:672-677. 
21 Cemazar M, Parkins C, Holder A, et al.: Electroporation of human microvascular endothelial cells: evidence for an antivascular mechanism of electrochemotherapy. Br J Cancer 2001;84:565-570.

22 Sersa G, Jarm T, Kotnik T, et al.: Vascular disrupting action of electroporation and electrochemotherapy with bleomycin in murine sarcoma. Br J Cancer 2008; 98:388-398

23 Mir LM, Roth C, Orlowski S, et al.: Systemic antitumor effects of electrochemotherapy combined with histoin compatibile cells secreting interleukin-2. J Immunother Emphasis Tumor Immunol 1995;17:30-38.

24 Sersa G, Miklavcic D, Cemazar M, et al.: Electrochemotherapy with CDDP on LPB sarcoma: comparison of the antitumor effectiveness in immunocompetent and immunodeficient mice. Bioelectrochem Bioenergy 1997;43:297-383.

25 Cabula C, Campana LG, Grilz G, et al.: Electrochemotherapy in the treatment of cutaneous metastases from breast cancer: a multicenter cohort analysis. Ann Surg Oncol 2015;22:442-450

26 Benavento R, Santoriello A, Perna G, et al.: Electrochemotherapy of cutaneous metastases from breas cancer in elderly patients: a preliminary report. BMC Surg 2012;12(suppl 1):6.
27 Matthiessen LW, Johannesen HH, Hendel HW, et al.: Electrochemotherapy for large cutaneous recurrence of breast cancer: a phase II clinical trial. Acta Oncologica 2012;51:713-721.

28 Kreuter A, van Eijk T, Lehmann P, et al.: Electrochemotherapy in advanced skin tumors and cutaneous metastases - a retrospective multicenter analysis. J Dtsch Dermatol Ges 2014;13:308-315.

29 Campana LG, Galuppo S, Valpione S, et al.: Bleomycin electrochemotherapy in elderly metastatic breast cancer patients: clinical outcome and management considerations. J Cancer Res Clin Oncol 2014;140:15571565.

30 Spratt DE, Gordon Spratt EA, Wu S, et al. Efficiency of skin-directed therapy for cutaneous metastases from advanced cancer: a meta-analysis. J Clin Oncol 2014; 32:3144-3155.

31 Sersa G, Miklavcic D, Cemazar M, et al. Electrochemotherapy in treatment of tumours. Eur J Surg Oncol 2008;34:232-240.

32 Moller M, Salwa S, Soden D, et al.: Electrochemotherapy as an adjunct or alternative to other treatments for unresectable or in-transit melanoma. Expret Rev Anticancer Ther 2009;9:1611-1630.
33 Gehl J: Electroporation: theory and methods, perspectives for drug delivery, gene therapy and research. Acta Physiol Scand 2003;177:437-447.

34 Snoj M, Cemazar M, Slekovac Kolar B, et al.: Effective treatment of multiple unresectable skin melanoma metastases by electrochemotherapy. Croat Med J 2007;48: 391-395.

35 Girelli R, Prejanò S, Cataldo I, et al.: Feasibility and safety of electrochemotherapy (ECT) in the pancreas: a pre-clinical investigation. Radiol Oncol 2015;49:147154.

36 Tafuto S, von Arx C, De Divitiis C, et al.: Electrochemotherapy as a new approach on pancreatic cancer and on liver metastases. Int J Surg 2015;21(suppl 1):78-82.

37 Cabula C: Neoadjuvant electrochemotherapy of breast cancer: our experience on first case treated in Italy. Updates Surg 2013;65:325-328

38 Campana LG, Valpione S, Falci C, et al.: The activity and safety of electrochemotherapy in persistent chest wall recurrence from breast cancer after mastectomy: a phase-II study. Breast Cancer Res Trat 2012;134:11691178.

39 Wichtowski M, Murawa D, Litwiniuk M, et al.: Initial experiences of the use of electrochemotherapy in the treatment of skin metastases. Nowotwory J Oncol 2016;66:1-9. 